\title{
AVERIGUACION DE DOMICILIO EN EL EXTRANJERO: COMENTARIO AL AUTO DE LA AUDIENCIA PROVINCIAL DE CORDOBA, DE 17 DE JUNIO DE 2020
}

\author{
RESEARCH OF ADDRESS ABROAD: COMMENTARY \\ TO THE JUDICIAL DECREE OF THE PROVINCIAL COURT \\ OF CORDOBA, OF 17TH JUNE 2020
}

\author{
Gloria Pérez de Colosía y LÁzaro \\ Abogado del Ilustre Colegio de Abogados de Murcia \\ Miembro de la Red Española Europea de expertos en Derecho Internacional Privado
}

Recibido: 19.11.2020 / Aceptado: 04.12.2020

DOI: https://doi.org/10.20318/cdt.2021.6010

\begin{abstract}
Resumen: Todo procedimiento judicial debe necesariamente iniciarse con la notificación de este a la parte contraria, lo que en ocasiones puede ser un problema de compleja resolución si se desconoce el domicilio del demandado o este es incorrecto, pues es necesario salvaguardar tanto el derecho de defensa como el derecho a una tutela judicial efectiva. En procesos transfronterizos esta situación puede agravarse ante la falta de instrumentos de los órganos judiciales del Estado de origen. El presente comentario analiza los mecanismos judiciales para la averiguación del domicilio en casos internacionales, con base en el auto dictado por la Audiencia Provincial de Córdoba ante la omisión, por parte del Tribunal de instancia, de llevarlos a cabo y acodar el archivo del procedimiento.
\end{abstract}

Palabras clave: Reglamento (CE) 1393/2007, Reglamento (CE) 1206/2001, notificación resoluciones judiciales, averiguación de domicilio, cooperación judicial internacional en materia civil.

Abstract: All legal proceedings must by necessity begin with the notification of the opposing party, which can sometimes be a complex problem to resolve if the defendant's domicile is unknown or is incorrect, since it is necessary to safeguard both the right to defence and the right to effective judicial protection. In cross-border proceedings, this situation may be aggravated by the lack of legal instruments of the judicial bodies of the state of origin. This essay analyzes the judicial mechanisms for the investigation of domicile in international cases, based on the order issued by the Provincial Court of Córdoba due to the omission, on the part of a lower court, to execute such mechanisms and agree to annul the procedure.

Keywords: Regulation (EC) 1393/2007, Regulation (EC) 1206/2001, notification of judicial documents, address enquiries, international judicial cooperation in civil matters.

Sumario: I Introducción. 1. Los datos. ¿Dónde nos encontramos? 2.- ¿A qué nos enfrentamos? II. Notificación en el extranjero a persona demandada. 1. ¿Cómo hemos llegado a esto? 2. Instrumentos legales internacionales para la notificación (actos de comunicación) A) En el ámbito de la Unión Europea B) En el ámbito extraeuropeo C) En el resto del mundo D) ¿Qué obligación y hasta donde llegan los límites del país receptor a la hora de practicar la notificación o el traslado? 3.- Instrumentos legales internacionales para la obtención de prueba A) En el ámbito de la Unión Europea B) En el ámbito extraeuropeo C) En el resto del mundo. 4. Instrumentos legales en el derecho internacional privado español para la notificación para la obtención de prueba. III. ¿Qué pudo hacer el juzgado de instancia y no hizo? IV. Conclusiones finales. 


\section{Introducción}

\section{Los datos. ¿Dónde nos encontramos?}

1. El objeto del presente comentario parte del Auto dictado por la Audiencia Provincial de Córdoba, Sección Primera, de 17 Junio $2020^{1}$ por el que se estima uno de los tres motivos del recurso de apelación interpuesto contra el Auto dictado por el Juzgado de Primera Instancia e Instrucción número 10 de Córdoba, de 23 Octubre 2019, mediante el cual se había acordado el archivo del procedimiento "por ilocalización del deudor". El Auto de la Audiencia de Córdoba acoge el argumento de apelación del recurrente en cuanto a que el juzgado de primera instancia, teniendo la obligación de hacerlo, no practicó todas las diligencias que le impone el artículo 161.4 último párrafo de la Ley de Enjuiciamiento Civil, en virtud de la remisión que hace al artículo 156 de la misma norma, y procedió sin embargo a dictar auto de archivo del procedimiento, privando a la parte demandante de su derecho a una tutela judicial efectiva.

2. Sin embargo, y esto será fundamental a efectos de la aplicabilidad del Reglamento (CE) 1393/2007 de 13 de noviembre de 2007 relativo a la notificación y al traslado en los Estados miembros de documentos judiciales y extrajudiciales en materia civil y mercantil o del Convenio de la Haya de 15 de noviembre de 1965 sobre la Notificación o Traslado en el Extranjero de Documentos Judiciales y Extrajudiciales en Materia Civil o Comercial, no nos situamos en el supuesto del artículo 156 de la Ley de enjuiciamiento civil, es decir, cuando el demandante desde el mismo origen de la demanda, indica que le es imposible indicar un domicilio (domicilio desconocido), sino en el supuesto del artículo 161.4, último párrafo de la misma norma legal, esto es, cuando intentada la notificación en el domicilio o lugar de trabajo indicado por el demandante, el demandado no residiera o trabajara allí y, una vez consultadas personas allí encontradas, bien por el letrado de la Administración de Justicia, funcionario o procurador, estas no hubieran podido facilitar ningún otro domicilio. El artículo 161.4 de la Ley de Enjuiciamiento Civil nos remite entonces a su artículo 156, luego su aplicación será igualmente imperativa, pero la particularidad de no partir de un domicilio desconocido será clave, como decía, para poder aplicar los mencionados instrumentos legales, dado que en su artículo 1.2 recoge "el presente Reglamento no se aplicará cuando el domicilio de la persona a la que haya de notificarse o trasladarse el documento sea desconocido".

\section{2. ¿A qué nos enfrentamos?}

3. La "ilocalización del demandado" por la que el juzgado de primera instancia número Diez de Córdoba archiva el procedimiento es, sin duda, uno de los problemas que más nos aterran a los abogados cuando, después de horas de trabajo en la preparación de un asunto, nos enfrentamos al inconveniente de la notificación a la otra parte, con lo que eso conlleva de no iniciación del procedimiento, que si de por sí ya se preveía lento, descubrir que el domicilio proporcionado al juzgado para la práctica de la notificación es incorrecto, ha dejado de existir o simplemente el demandado ya no se encuentra allí, puede significar la pérdida del objeto del procedimiento sin ni siquiera haberse iniciado. Si le añadimos un elemento extranjero y que la notificación debe hacerse fuera de España, el desánimo es aún mayor, ante la dificultad que puede entrañar la localización de la nueva residencia del demandado, que pudiera incluso haberse trasladado a otro país. No hay que olvidar que la carga procesal de aportar cuantos datos se conozca del demandado y puedan ser útiles para su localización, recae sobre el demandante, presuponiéndose de este, que actúa de buena $\mathrm{fe}^{2}$, pero tampoco hay que obviar el mandato del articulo 152

\footnotetext{
${ }^{1}$ AAP Córdoba 17 Junio 2020 [ECLI:ES:APCO:2020:469A],

${ }^{2}$ A este respecto y por contra, interesante es la reflexión de la STS 287/2017 de 12 de Mayo respecto al existencia d una " $m a$ quinación fraudulenta" sobre la conducta del actor que pretende impedir o dificultar el emplazamiento al demandado, "una de las manifestaciones de la maquinación fraudulenta que permite la revisión de la sentencia es aquella que incurre quien ejercita una acción judicial cuando oculta el domicilio de la persona contra la que estaba dirigida, alegando que lo desconoce para interesar
} 
de la Ley de Enjuiciamiento Civil ${ }^{3}$ que hace responsable al letrado de la administración de la adecuada organización del servicio de los actos de comunicación, esto es, de las notificaciones y traslados de documentos judiciales.

4. Afortunadamente, en el derecho interno de cada Estado miembro, existen mecanismos judiciales para la averiguación del domicilio, pero ¿qué ocurre cuando la notificación debe hacerse fuera de España? ¿tienen las autoridades judiciales del Estado de origen acceso a los registros o servicios del Estado de destino para la averiguación del domicilio donde hay que notificar, o son los órganos judiciales del Estado de destino los que tienen que directamente deben llevar a cabo prácticas para dicha averiguación? ¿Puede el Reglamento (CE) n ${ }^{\circ}$ 1206/2001, relativo a la cooperación entre los órganos jurisdiccionales de los Estados miembros en el ámbito de la obtención de pruebas en materia civil o mercantil, ayudar a ello? Y en mataría de averiguación del domicilio ¿puede el Reglamento (CE) 1206/2001 de 28 de mayo de 2001, relativo a la cooperación entre los órganos jurisdiccionales de los Estados miembros en el ámbito de la obtención de pruebas en materia civil o mercantil aplicarse? ¿Y qué ocurre fuera del ámbito europeo? ¿Hizo el juzgado de primera instancia $n^{\circ} 10$ de Córdoba todo lo posible para la averiguación domiciliaria del demandado y que pudiera, por tanto, iniciarse el procedimiento? Veremos que las respuestas son diferentes dependiendo de en qué escenario territorial nos movamos.

\section{Notificación en el extranjero a persona demandada}

\section{1. ¿Cómo hemos llegado a esto?}

5. Empecemos por el principio. ¿Por qué es tan importante desarrollar un buen mecanismo de notificación, traslado de documentos, tanto judiciales como no judiciales, y práctica de prueba, más allá de los límites de un Estado, y por tanto desarrollar normativas supranacionales que lo faciliten? Porque las personas ya no nos estamos quietas y ese concepto de residir y morir donde se nace, ha quedado caduco. Es el dinamismo frente a la estaticidad. Es la actual globalización, iniciada con los procesos migratorios de la prehistoria y precipitada ya sin límites con la caída del Muro de Berlín en 19894, el colapso de la Unión Soviética y el fin de la guerra fría. Es la libre circulación de las personas.

6. En el Tratado Constitutivo de la Comunidad Económica Europea el 25 de Marzo de 1957 existían disposiciones relativas a la libre circulación de trabajadores y a la libertad de establecimiento, pero fue el Tratado de Maastricht de 7 de Febrero de 1992 el que introdujo el concepto de ciudadanía de la Unión Europea5. Así, en la actualidad y en el ámbito europeo, la libre circulación de las personas

que se le emplace por edictos y se sustancie el procedimiento en rebeldia (...)" < ECLI: ES:TS:2017:1789>. En el mismo sentido, la STS 833/2013 de 19 de diciembre que cataloga como maquinación fraudulenta "presentar la demanda de desahucio frente al arrendatario, como si éste siguiese viviendo en la vivienda que habia sido arrendada, y sin practicar las diligencias necesarias para la averiguación del domicilio, con el fin de lograr una sentencia firme condenatoria, y luego practicar las averiguaciones necesarias para obtener un domicilio en el trámite de ejecución de sentencia". <ECLI: ES:TS:2013:6499>

${ }^{3}$ Artículo 152 Ley 1/2000, de 7 de enero, de Enjuiciamiento Civil BOE núm. 7 de 08 de Enero de 2000: "1. Forma de los actos de comunicación. Respuesta. $1 .{ }^{\circ}$ Los actos de comunicación se realizarán bajo la dirección del letrado de la Administración de Justicia, que será el responsable de la adecuada organización del servicio.

${ }^{4}$ Para ampliar este aspecto' P. CoRelLA, Lecturer at Bachelor's Degree in International Business and Marketing (GNMI) " $L a$ caída del muro de Berlín fue el pistoletazo de salida a la globalización”. Noviembre 2019, y T. Friedman ganador del premio Pulitzer tres veces "The World Is Flat: Breve Historia del Mundo Globalizado del Siglo XXI / A Brief History of the Twenty-first Century" Farrar, Straus and Giroux Abril 2005.

${ }^{5}$ De conformidad con el artículo 9 del TUE y el artículo 20 del TFUE, será ciudadano de la Unión Europea, toda persona que tenga la nacionalidad de un Estado miembro, la cual se deriva de la aplicación de las disposiciones nacionales de dicho Estado. La ciudadanía de la Unión complementa la ciudadanía nacional sin sustituirla, y está constituida por un conjunto de derechos y deberes que vienen a sumarse a los derechos y deberes vinculados a la ciudadanía de un Estado miembro. C-135/08 Janko Rottmann/Freistaat Bayern. 
se garantiza en el Tratado de la Unión Europea (TUE), en el Tratado de Funcionamiento de la Unión Europea (TFUE) ${ }^{6}$, y en el artículo 45 de la Carta de los Derechos Fundamentales de la Unión Europea.

7. Consecuencia inmediata de la libre circulación de personas es, sin duda, el aumento de esa misma circulación, lo que lleva, entre otras cosas, a un incremento de matrimonios mixtos y familias transfronterizas y, por lo tanto, a la necesidad de reconocimiento de las decisiones judiciales y extrajudiciales extranjeras ${ }^{8}$ en materia civil que se han producido en un país y que, junto a la persona y las familias, también empiezan a circular por el mundo, a fin de que desplieguen sus oportunos efectos jurídicos y puedan ser ejecutable, no convirtiéndose en resoluciones claudicantes ${ }^{9}$.

8. Así, la reciente pero ya consolidada jurisprudencia del tribunal de Justicia de la Unión Europea garantiza, no sólo el desplazamiento de las personas sino también el reconocimiento de situaciones privadas en el espacio europeo, a través de la creación de instrumentos legales que unifican las normas de conflicto de leyes y el principio de mutuo reconocimiento ${ }^{10}$ para con este tipo de decisiones, y lo mismo ocurre respecto al resto de países con los que exista un convenio multilateral o bilateral.

9. Así configurado, el principio de reconocimiento mutuo ${ }^{11}$ aunque dado su carácter de excepción esté sujeto a dos condiciones y un límite que habrán de comprobarse y validarse ${ }^{12}$ es, por tanto, una pieza crucial para el correcto funcionamiento y desarrollo del sector procesal del Derecho Internacional Privado ${ }^{13}$, es decir, para el reconocimiento y ejecución de las situaciones jurídicas nacidas en un Estado miembro y que por, múltiples motivos, necesitan continuar existiendo y desplegando efectos en otro ${ }^{14}$.

${ }^{6}$ En concreto, en su Título II segunda parte (arts. 18-25), en el Título IV capítulo 1, artículos 45-48 sobre la libre circulación de las personas y en los artículos 49-62 sobre el derecho de establecimiento y la libre prestación de servicio

${ }^{7}$ E. LóPEZ-JACISTE. Profesora titular de Derecho Internacional y Relaciones Internacionales Universidad de Navarra Universidad. Marco jurídico de la libre circulación de personas en la Unión Europea. Carlos III de Madrid. 28 y 29 de septiembre 2011

${ }^{8}$ Esto es, la solución proporcionada por una autoridad extranjera que se quiere reconocer en el foro, entendiéndose por tal "el acto de voluntad de una autoridad pública extranjera que resuelve una cuestión de Derecho internacional privado" $\mathrm{P}$. MaYer/V. Heuzé, Droit international privé, Montchrestien, París, 7ª ed., 2001, págs. 241-243; P. MaYer, La distinction entre règles et décisions et le droit international privé, Dalloz, París, 1973, recogido por A. L. CALvo CARAVACA y J. CARRASCosa GonZÁLEZ. Ejecución de resoluciones patrimoniales en la unión europea: el Reglamento 44/2001 de 22 diciembre 2000 International Law: Revista Colombiana de derecho Internacional Nº. 3, 2004, págs.363-460.

${ }^{9}$ Cuando hablamos de situaciones claudicantes en el ámbito internacional nos referimos a aquellas situaciones que son válidas en un Estado, pero que pueden no serlo en otros con los que el asunto tiene vínculos relevantes. Véase con carácter general F. CALvo ¿Qué es una situación claudicante en el ámbito internacional? Confilegal.com 30 Abril 2017.

${ }^{10}$ M.D. ORTOZ VIDAL El principio de mutuo reconocimiento en el ámbito de la UE y los límites a la libre circulación ¿̇mecanismo conciliador en tiempos revueltos? Revista de Derecho Civil http://nreg.es/ojs/index.php/RDC ISSN 2341-2216 vol. II, núm. 3 (julio-septiembre, 2015), pp. 177-197.

${ }^{11}$ Resolución del Consejo, de 28 de octubre de 1999, sobre el reconocimiento mutuo [Diario Oficial C 141, de fecha 19 mayo 2000].

${ }^{12}$ I. Blázquez RodríGuez, "Libre circulación de personas y derecho internacional privado: un análisis a la luz de la jurisprudencia del tribunal de justicia de la unión europea”, Cuadernos de Derecho Transnacional (Octubre 2017), Vol. 9, № 2, pp. 106-126.

${ }^{13}$ Tras el Convenio de Bruselas de 27 de septiembre de 1968 y el Tratado de Ámsterdam de 1997 ha desaparecido paulatinamente el exequátur al establecerse correlativamente el reconocimiento mutuo en materia civil y mercantil. Ad. exemplum, Reglamento (UE) n ${ }^{\circ}$ 1215/2012, de 12 de diciembre de 2012, relativo a la competencia judicial, el reconocimiento y la ejecución de resoluciones judiciales en materia civil y mercantil (DOUE 351, de 20 de diciembre de 2012); Reglamento 4/2009, Reglamento (CE) 4/2009, de 18 de diciembre 2008, relativo a la competencia, la ley aplicable, el reconocimiento y la ejecución de las resoluciones y la cooperación en materia de obligaciones alimenticias (DOUE L 7, 10 de enero de 2009); Reglamento 2201/2003, Reglamento (UE) no 650/2012 de 4 de julio de 2012 relativo a la competencia, la ley aplicable, el reconocimiento y la ejecución de las resoluciones, a la aceptación y la ejecución de los documentos públicos en materia de sucesiones mortis causa y a la creación de un certificado sucesorio europeo (DOUE L 201, de 17 de julio 2012).

${ }^{14} \mathrm{El}$ modo de funcionamiento de este principio lo explica así el profesor J. CARRASCOSA González "el Tribunal de Justicia de la Unión Europea ha dado carta de naturaleza al muy célebre "principio del mutuo reconocimiento de situaciones legales creadas en un Estado miembro en materias de Derecho privado". Funciona de esta manera: una situación jurídica legalmente creada en un Estado miembro "de origen" con arreglo a una Ley estatal determinada, debe ser "reconocida" en los demás Estados miembros para que de ese modo no se perjudiquen las libertades de circulación propias de la UE (STJCE 30 marzo 1993, Konstantinidis; STJCE 9 marzo 1999; STJCE 5 noviembre 2002, Überseerin; STJCE 30 septiembre 2003, Inspire 
Consecuentemente, una vez podemos circular libremente y llevar con nosotros las situaciones jurídicas que hayan nacido en nuestro país de origen y hacerlas valer en el país destino, está garantizado sin duda, el derecho y la posibilidad de poder litigar más allá de nuestras fronteras, desafiando de este modo el carácter local de la justicia de antaño. Es a esto a lo que nos enfrentamos, a que nuestra petición de auxilio judicial hecha en Córdoba pueda llegarle sin problemas al demandado cuando este se encuentra en un país distinto al nuestro. Dado que el juzgado $\mathrm{n}^{\mathrm{o}} 10$ de Córdoba no hizo todo lo posible para que esto sucediera, la audiencia Provincial le remitió de nuevo el procedimiento "dejando sin efecto el archivo allí acodado al objeto de que se proceda a la averiguación del domicilio del demandado conforme al artículo 156 de la Ley de Enjuiciamiento Civil (...)”

\section{Instrumentos legales internacionales para la notificación (actos de comunicación)}

10. Vamos a continuación a analizar con qué instrumentos legales internacionales contaba el juzgado de primera instancia número 10 de Córdoba para la solicitud de notificación de la demanda en el extranjero, así como las obligaciones del país de destino para practicar dicha notificación una vez recibida y aceptada correctamente. No analizaré cada uno de ellos, pudiéndose estudiar ampliamente el tema de las notificaciones y traslado de documentos judiciales y extrajudiciales al extranjero, así como el de la obtención de prueba en el extranjero, que expondré a continuación, en el extenso y acertado monográfico de Alfonso- Luis Caravaca y Javier Carrascosa González "Asistencia judicial internacional. Régimen jurídico en derecho internacional privado europeo y español"15.

\section{A) En el ámbito de la Unión Europea}

11. Si la demanda hubiera tenido su destino en el ámbito de la Unión europea, de la que forman parte 28 países, tenemos el Reglamento 1393/2007, de 13 de noviembre, relativo a la notificación y al traslado entre Estados miembros de la UE de documentos judiciales y extrajudiciales en materia civil o mercantil ${ }^{16}$, siendo también de aplicación respecto a Dinamarca, aunque con ciertos matices, por vía del acuerdo bilateral celebrado entre la Unión Europea y este Estado ${ }^{17}$. En la definición de documentos extrajudiciales que da el Reglamento, y según ha ido desarrollando la jurisprudencia del TJUE, se incluyen también los documentos notariales ${ }^{18}$, e incluso los documentos privados cuya transmisión formal al destinatario en el extranjero sea necesaria para el ejercicio efectivo o la salvaguarda de un derecho ${ }^{19}$. Puede ampliarse más sobre los documentos privados en el trabajo de la profesora María Jesús Elvira Benayas ${ }^{20}$.

Art; STJCE 2 octubre 2003, García Avello; STJUE 14 octubre 2008, Grunkin-Paul; STJUE 22 diciembre 2010, C-208/09, Wittgenstein). De ese modo, por ejemplo, una sociedad mercantil válidamente creada en Irlanda debe considerarse válida y eficaz en España, aunque las autoridades irlandesas hayan aplicado normas legales distintas a las que habrian aplicado las autoridades españolas."

${ }^{15}$ A.L Calvo Caravaca Catedrático de $\mathrm{D}^{\mathrm{o}}$ internacional privado Universidad Carlos III de Madrid y J. Carrascosa GonzÁlez Catedrático de $\mathrm{D}^{\mathrm{o}}$ internacional privado Universidad de Murcia “Asistencia judicial internacional. Régimen jurídico en derecho internacional privado europeo y español” http://www.accursio.com/private/uploads/111_ASISTENCIA_JUDICIAL_INTERNACIONAL_2017.pdf

${ }^{16}$ Reglamento (CE) núm. 1393/2007 del Parlamento Europeo y del Consejo, de 13 de noviembre de2007, relativo a la notificación y al traslado en los Estados miembros de documentos judiciales y extrajudiciales en materia civil o mercantil por el que se deroga el Reglamento (CE) núm. 1348/2000 del Consejo, (DO L 324, 10 diciembre 2007).

${ }^{17}$ Acuerdo de 19 de Octubre de 2005 entre la Comunidad Europea y Dinamarca (Decisión del Consejo de 27 de Abril de 2006)

${ }^{18}$ STJUE as.C-14/08 Sala tercera de 25 de Junio de 2009. Roda Golf \& Beach Resort SL <ECLI:EU:C:2009:395>; RDGRN de 27 de febrero de 2012

${ }^{19}$ STJUE as. C_223/14 Sala Primera, de 11 de noviembre de 2015. Tecom Mican, S.L., y José Arias Domínguez.<ECLI:EU:C: 2015:744>.

${ }^{20}$ M.J: Elvira Benayas Profesora contratada doctora de la Universidad Autónoma de Madrid. "La notificación en el extranjero de documentos extrajudiciales: los documentos privados". Cuadernos de Derecho Transnacional (Octubre 2018), Vol. 10, $\mathrm{N}^{\mathrm{o}} 2$, pp. 827-835. 
12. El Reglamento $1393 / 2007$, de 13 de noviembre, relativo a la notificación y al traslado entre Estados miembros de la UE de documentos judiciales y extrajudiciales en materia civil o mercantil, es de aplicación imperativa y no facultativa, lo que quiere decir que, si el país destino es un Estado miembro, no se puede acudir a las vías de notificación recogidas en las normas nacionales del Estado miembro de origen, ya que el Reglamento impera por encima de estas, aunque la forma de practicar la notificación sigue siendo competencia exclusiva e cada Estado miembro. El canal principal de notificación es entre los organismos judiciales designados por cada país -organismos transmisores y organismos receptores competentes-, existiendo otros canales, siempre con precisiones, como la vía consular o diplomática (artículos 12 y 13), la vía postal directa (artículo 14) o la notificación por parte del interesado a través de funcionarios competentes del Estado de destino (artículo 15). En la referencia indicada a pie de página $^{21}$ puede accederse a la web de eur-lex.europa, donde se encuentra alojado el manual que la Comisión elaboró para facilitar el uso de este Reglamento según mandato recogido en su C-19. Mediante un sistema de banderas puede pincharse en cada Estado miembro y se despliega la información referente a cuestiones concretas en ese Estado. Así, puede conocerse los medios de recepción de documentos, los datos de la autoridad central, los idiomas que se aceptan para la transmisión del documento, los plazos del derecho interno para la notificación del documento, las formas de notificación admitidas, los gastos de traslado en su caso e incluso datos bancarios de ingreso, o como actúa la autoridad judicial de cada Estado miembro ante la incomparecencia del demandado (artículo 9). Es esta una forma muy fácil y segura, pues se presupone que la información se mantiene siempre actualizada y es veraz, para conocer muy rápidamente cómo y en qué condiciones debe hacerse la petición de notificación o de traslado de un documento, judicial o extrajudicial. Además, todas las solicitudes se hacen por medio de formularios normalizados contenidos en los anexos del Reglamento para la unificación en todos los Estados miembros, por lo que su conocimiento por parte de los juzgados no debe obviarse. Una vez practicada la notificación o traslado de documento por parte de Estado receptor, este enviará un certificado que así lo acredite al Estado emisor.

13. Este Reglamento se encuentra en la Comisión de Servicios Jurídicos en vías de modificación, con objeto de mejorar la eficiencia y la rapidez de los procedimientos judiciales con implicaciones transfronterizas en materia civil y mercantil, y entre los elementos principales de propuesta de mejora se articula el intercambio digital de documentos, es decir, que todos la comunicación e intercambio de documentos se realice vía electrónica a través de una infraestructura de comunicación y, en lo que atañe a este trabajo que, ante un destinatario sin dirección conocida, "los Estados miembros estarían obligados a ayudar a localizar el paradero del destinatario". Es preciso indicar la aprobación del nuevo Reglamento (UE) 2020/1784 del Parlamento Europeo y del Consejo de 25 de noviembre de 2020 relativo a la notificación y traslado en los Estados miembros de documentos judiciales y extrajudiciales en materia civil o mercantil, que será de aplicación en su integridad a partir del 1 de julio 2022.

\section{B) En el ámbito extraeuropeo}

14. Si la demanda hubiera tenido su destino en un ámbito extraeuropeo a alguno de los 83 países que forman parte del Convenio de la Haya de 15 de noviembre de 1965 relativo a la notificación o traslado en el extranjero de documentos judiciales y extrajudiciales en materia civil o comercial ${ }^{22}$, y que sustituye al anterior Convenio relativo al procedimiento civil, hecho en la Haya el 1 de marzo de 1954, serán las vías allí establecidas las que deben seguirse. El sistema es muy parecido al que establece el

\footnotetext{
${ }^{21}$ Las normas básicas de funcionamiento de este Reglamento pueden encontrarse en https://e-justice.europa.eu/content_ serving_documents-373-es.do y el manual práctico de la Comisión UE en DOCE L 125 de 13 de mayo 2002 https://eur-lex. europa.eu/legal-content/ES/TXT/?uri=OJ:L:2002:125:TOC

${ }^{22}$ Instrumento de ratificación del Convenio relativo a la notificación o traslado en el extranjero de documentos judiciales y extrajudiciales en materia civil o comercial, hecho en La Haya el 15 de noviembre de 1965. BOE 203, de 25 de agosto de 1987, páginas 26197 a 26206.
} 
Reglamento 1393/2007, de 13 de noviembre, relativo a la notificación y al traslado entre Estados miembros de la UE de documentos judiciales y extrajudiciales en materia civil o mercantil, solo que la vía principal de remisión de un acto de comunicación es a través de la "Autoridad Central" que cada Estado contratante tiene que designar, en lugar de entre los propios orgasmos judiciales de los distintos Estados miembros. Una vez practicada la notificación se remitirá un certificado al Estado contratante solicitante. En la nota a pie de página ${ }^{23}$ puede verse la dirección donde consultar todas las autoridades centrales de cada Estado contratante, con inclusión el nombre del encargado, dirección, coste del traslado del documento en su caso, cuestiones sobre la traducción y otras informaciones. Otras vías de remisión alternativa pueden ser la vía consular o diplomática directa o indirecta (artículos 8 y $9 \mathrm{CH}$ ), la vía postal (artículo 10 a)), la vía de comunicación directa entre funcionarios judiciales o personas competentes (artículo 10 b)), o la vía de remisión directa entre el interesado y los funcionarios judiciales o personas competentes (artículo 10 c)). Por lo tanto, de ser el país destino de la demanda a notificar uno de los países acogidos a este convenio, el juzgado de primera instancia número 10 de Córdoba tuvo ese instrumento para intentar la notificación de la demanda antes, antes de dictar Auto de archivo.

15. A diferencia del Reglamento $1393 / 2007$, este convenio permite al juez continuar con el proceso aun cuando no haya quedado acreditada la práctica de la notificación (artículo 15), siempre que se den cuatro condiciones, primero, que la notificación se haya practicado según los modos previstos en el convenio, segundo, que desde la fecha de envío del documento por el Estado contratante origen haya transcurrido un plazo de al menos seis meses, tercero, que el juez del Estado contratante de origen a pesar de haber realizado todas las diligencias oportunas en el Estado contratante requerido no haya conseguido obtener el certificado de notificación y cuarto, que el juez del Estado contratante de origen lo haya expresamente así declarado y siempre que se cumplan las tres condiciones anteriores. En la página mencionada puede también consultarse qué Estado contratante ha expresado esta circunstancia.

16. Como singularidad, en Estados Unidos la transmisión debe llevarse a cabo haciendo uso del servicio privado con el que el departamento de Justicia norteamericano tiene externalizado esta función, la empresa Process Forwarding International, ABC legal, abonando una tasa que podrá incluirse en costas de haberlas ${ }^{24}$.

17. Respecto a las normas de procedimiento civil en el ámbito extraeuropeo, encontramos podemos acudir también al Convenio de la Haya de 1 de Marzo de 1954 sobre procedimiento civil ${ }^{25}$, que solo contempla la petición consular o diplomática del Estado exhortante dirigida a la autoridad designada por el Estado exhortado para que a su vez practique la notificación o traslado al demandado.

\section{C) En el resto del mundo}

18. Si el documento judicial hubiera debido notificarse o trasladarse a alguno de los países que quedan fuera del ámbito de aplicación, tanto del Reglamento 1393/2007 como del Convenio de la Haya de 15 de noviembre de 1965, el juzgado de primera instancia numero Diez de Córdoba tenía a su disposición varios instrumentos, o bien el Tratado Multilateral de la Convención Interamericana sobre exhortos y cartas rogatorias, hecho en Panamá el 30 de Enero de $1975^{26}$, elaborado en el marco de la Organización de los Estados Americanos y del que España es el único Estado europeo miembro, o bien alguno de los Tratados bilaterales que España ha firmado en el marco de la notificación y obtención de prueba en el

\footnotetext{
${ }^{23}$ Las normas básicas sobre el funcionamiento de este convenio pueden encontrarse en https://www.hcch.net/es/instruments/conventions/specialised-sections/service.

${ }^{24} \mathrm{https}$ ://www.abclegal.com/international/hague-service-convention.

${ }^{25}$ Convenio de 1 de marzo de 1954 sobre el Procedimiento Civil. http://www.prontuario.org/prontuario/es/Civil/Consulta/ Convenio-de-La-Haya-sobre-procedimiento-civil-de-1-de-marzo-de-1954.

${ }^{26} \mathrm{http}: / /$ www.oas.org/juridico/spanish/tratados/b-36.html
} 
extranjero, tales como el Tratado entre el Reino de España y la República Popular China de 2 de mayo de $1992^{27}$, el Convenio hispano-portugués de 19 de noviembre de $1997^{28}$, el Convenio hispano-tailandés de 15 de Junio de $1998^{29}$, el Convenio hispano-tunecino de 24 de septiembre de $2001^{30}$, el Convenio de asistencia judicial en materia civil y mercantil entre el Reino de España y la Republica Dominicana de 15 de septiembre de $2003^{31}$, el Convenio hispano-argelino de 24 de Febrero de $2005^{32}$, o el Convenio hispano-mauritano de 12 de septiembre de $2006^{33}$. También le podía haber sido de utilidad la utilización de la web de la Red Iberoamericana de cooperación jurídica internacional, Iberred ${ }^{34}$.

\section{D) ¿Qué obligación y hasta donde llegan los límites del país receptor a la hora de practicar la no- tificación o el traslado?}

19. ¿Pueden los organismos judiciales practicar sus propias diligencias en caso de que el domicilio facilitado por el país emisor sea incorrecto, incompleto, ya no exista o no se encuentre en él al demandado? Del recorrido hecho por los distintos instrumentos normativos, encuentro que a mayor cercanía geográfica e institucional más fácil es la cooperación y mayores las facultades del país receptor de la petición de notificación o traslado de documento. Con carácter general, el Reglamento 1393/2007, de 13 de noviembre, relativo a la notificación y al traslado entre Estados miembros de la UE de documentos judiciales y extrajudiciales en materia civil o mercantil, establece en su C (9) que "la notificación o traslado de un documento debe efectuarse cuanto antes, $y$, en cualquier caso, en el alzo de un mes desde su llegada al organismo receptor" y en su C (14) que "El organismo receptor seguirá adoptando todas las medidas necesarias para efectuar a notificación o traslado del documentos también en casos en que no haya sido posible efectuar la notificación o el traslado en el plazo de un mes (...). No obstante, con el fin de evitar que corresponda al organismo receptor una obligación ilimitada de adoptar medidas para efectuar la notificación o traslado del documento, el organismo transmisor debe poder especificar un plazo en el formulario normalizado a partir del cual deja de requerirse la notificación o el trasla$d o$ ". Esto es, en mi opinión, clave para determinar hasta dónde puede llegar la obligación del Estado de destino a la hora de practicar una notificación o traslado, pues el propio Reglamento 1393/2007 marca un primer limite no imponiéndole una "obligación ilimitada", pero al mismo tiempo le permite seguir adoptando medidas para la notificación. En el mismo sentido se expresa el artículo 7.2b) “continuará (el organismo receptor) realizando todas las diligencias necesarias para efectuar la notificación o traslado del documento, a menos que el organismo transmisor indique otra cosa, cuando la notificación o el traslado parezcan ser posibles en un plazo razonable."

20. En el caso de que la información facilitada por el país emisor sea deficiente, el organismo receptor debe ponerlo en conocimiento del primero "por el medio más rápido posible" (artículo 6.2), es decir, lo devolverá al juzgado de primera instancia número 1 de Córdoba y tendrá este que practicar las diligencias que considere oportunas para recabar la información complementaria o corregir la deficiente, probablemente requiriendo para ello al demandante. En cualquier caso, y esto es importante a efectos de contestar a las preguntas hechas más arriba, "el organismo receptor procederá a efectuar o a que se efectúe la notificación o traslado del documento, bien de conformidad con el Derecho interno del Estado miembro requerido o bien según la forma particular solicitada por el organismo transmisor, siempre que esta no sea incompatible con el derecho interno de ese Estado miembro" (artículo 7.1).

\footnotetext{
${ }^{27} \mathrm{https}: / /$ www.boe.es/diario_boe/txt.php?id=BOE-A-1994-2077

${ }^{28} \mathrm{https}: / /$ www.boe.es/diario_boe/txt.php?id=BOE-A-1999-1363

${ }^{29} \mathrm{https} / / /$ www.boe.es/diario_boe/txt.php?id=BOE-A-1999-10229

${ }^{30} \mathrm{https}: / / \mathrm{www}$. boe.es/diario_boe/txt.php?id=BOE-A-2003-4239

${ }^{31} \mathrm{https} / / /$ www.boe.es/diario_boe/txt.php?id=BOE-A-2003-19568

${ }^{32} \mathrm{https}: / /$ www.boe.es/diario_boe/txt.php?id=BOE-A-2006-7733

${ }^{33} \mathrm{https}$ ://www.boe.es/diario_boe/txt.php?id=BOE-A-2006-19347

${ }^{34} \mathrm{https}: / /$ www.iberred.org/
} 
21. En consecuencia, por un lado, cada país seguirá su propio derecho interno para proceder a la notificación y si este derecho interno indica que la notificación, antes de determinarse fallida, se intentará tres veces, o si el derecho interno de un país regula que la notificación se hará vía correo electrónico o vía telefónica, así deberá hacerse, lo que hará sin duda que, dependiendo de ese derecho interno, resulte más fácil la notificación en unos países que en otros. No obstante, de vuelta a España, habrá que tener en cuenta la opinión del Tribunal Constitucional respecto a ciertos tipos de notificaciones, como la vía correo electrónico. Lo analizaré más adelante.

22. Para salvaguardar el derecho a una tutela judicial efectiva, el TJUE no admite ciertas prácticas de notificación contrarias a este principio. Así, por ejemplo, en el C-325/11 párrafo 32 y 40, el TJUE rechaza el mecanismo de notificación establecido en el artículo $1135^{5}$ del código polaco que recoge que, una vez notificado el demandado en el extranjero este debe designar un representante en el procedimiento del país donde se está resolviendo el procedimiento, en este caso Polonia, y de no hacerlo, se entenderán notificadas todas las siguientes resoluciones judiciales (notificaciones ficticias). ${ }^{35}$

23. Por otro lado, lo regulado en el artículo 7.1 y 7.2b) permite al organismo transmisor, en nuestro caso el juzgado de primera instancia número Diez de Córdoba, seguir controlando la forma de notificación , puesto que mantiene la potestad de elegir como hacer la notificación, por lo que, si tiene la diligencia en averiguar las alternativas de notificaron en el país receptor, podrá elegir el más conveniente para el demandado al que debe notificar, no cayendo así en la inactividad que le achacó la Audiencia Provincial.

24. En consecuencia con lo anterior, si para la práctica de la notificación y traslado del documento, por un lado, se atiende al derecho interno del país receptor, y por otro, el país trasmisor tiene facultades para controlar la forma de notificación, ¿podría llegarse a dar una notificación internacional mediante edictos si el derecho interno del país receptor así lo contempla y el país transmisor así lo ha pedido? Por ejemplo, la ley de enjuiciamiento civil alemana (la Zivilprozessordung), regula en su artículo 185 disposiciones en materia de notificación edictal y nada, en el literal de este artículo limita que así pueda $\operatorname{ser}^{36}$.

25. Si nos movemos en el contexto del Convenio de la Haya lo único que recoge el texto respecto a la autonomía del Estado contratante requerido a la hora de practicar la notificación o traslado está en el artículo $5 \mathrm{CH}$ "La Autoridad Central del Estado requerido procederá u ordenará proceder a la notificación o traslado del documento: a) ya según las formas prescritas por la legislación del Estado requerido para la notificación o traslado de los documentos otorgados en este país y que se destinen a personas que se encuentren en su territorio, b) ya según la forma particular solicitada por el requirente, siempre que no resulte incompatible con la ley del Estado requerido", que en este sentido es similar a la regulación del Reglamento 139372007, es decir cada país contratante seguirá su propio derecho interno para proceder a la notificación al mismo tiempo que se permite a la autoridad central de origen, seguir

${ }^{35}$ STJUE C-325/11 Pfos. 32 y 40 Sala primera de 19 Diciembre 2012. Alder-Ortowoska <ECLI:EU:C:2012:824> "Pues bien, dado que estos medios de transmisión de documentos judiciales son los únicos previstos, con carácter exhaustivo, en el sistema establecido por dicho Reglamento, procede declarar que éste no contempla en absoluto la posibilidad y, por tanto, se opone a un procedimiento de notificación o traslado ficticio como el que está en vigor en Polonia en virtud del artículo $1135^{5}$ del Código de procedimiento civil.", y "Pues bien, en este contexto, es preciso declarar que un mecanismo de notificación o traslado ficticio, como el que estable el artículo $1135^{5}$ del Código de procedimiento civil, resulta incompatible con la realización del objetivo de protección del derecho de defensa perseguido por el Reglamento 1393/2007."

${ }^{36}$ Zivilprozessordung (ZPO) «Artículo 185. Notificación edictal: La notificación puede tener lugar mediante comunicación pública (notificación edictal) cuando: 1 se desconozca el lugar de residencia del interesado y no sea posible la notificación a un representante o a un apoderado a efectos de notificaciones, 2.tratándose de personas jurídicas obligadas a inscribir una dirección comercial nacional en el Registro Mercantil, no sea posible la notificación ni en la dirección inscrita, ni en la dirección inscrita en el Registro Mercantil de la persona facultada para recibir las notificaciones, ni tampoco en ninguna otra dirección nacional conocida sin que sea necesario realizar averiguaciones, 3.no quepa una notificación en el extranjero o con toda probabilidad resultará fallida, o 4.la notificación no pueda llevarse a cabo porque el lugar de la notificación sea el domicilio de una persona que, de conformidad con los artículos 18 a 20 de la Ley del Poder Judicial, no esté sujeta a la jurisdicción alemana." 
controlando la forma de notificación en caso de querer disponer de alguna específica y admitida por la autoridad central del país de destino.

26. En cualquier caso, la respuesta final a cuál es el límite del país receptor para practicar la notificación o traslado o cuántas diligencias están obligados a practicar, será distinta dependiendo siempre del país de que se trate, tanto si nos encontramos en el escenario del Reglamento 1393/2007, de 13 de noviembre, relativo a la notificación y al traslado entre Estados miembros de la UE de documentos judiciales y extrajudiciales en materia civil o mercantil, como en el del Convenio de la Haya de 15 de noviembre de 1965 relativo a la notificación o traslado en el extranjero de documentos judiciales y extrajudiciales en materia civil o comercial o en el escenario de otros convenios bilaterales o multilaterales con el resto de países, y la información correcta concreta y actualizada, se puede encontrar alojada en los sitios web referenciados.

\section{Instrumentos legales internacionales para la obtención de prueba}

27. Si, una vez hecha la petición de notificación en país extranjero y el domicilio facilitado por el demándate resulta no ser correcto o el demandado ya no reside o trabaja allí, pude acudirse a los instrumentos para la obtención de pruebas que a lo largo de los años se han ido confeccionando como consecuencia de la necesidad que tiene un órgano jurisdiccional que debe decidir sobre un asunto con elemento extranjero, de realizar en otro país una diligencia probatoria, tal como tomar declaración a unos testigos o practicar una prueba pericial. Nos interesan los instrumentos desarrollados al efecto en tanto en cuanto nos permitan la averiguación del domicilio del demandado, que es la cuestión que nos ocupa.

\section{A) En el ámbito europeo}

28. Así, en el ámbito europeo, tenemos el Reglamento 1206/2001, de 28 de Mayo, relativo a la cooperación entre los órganos jurisdiccionales de los Estados miembros en el ámbito de la obtención de pruebas en materia civil o mercantil ${ }^{37}$, en el que en esta ocasión Dinamarca queda excluido C (22). Prevalece sobre cualquier convenio internacional, bilateral o multilateral, pero permite que los Estados miembros entre sí adopten medidas que mejoren la obtención de pruebas siempre que compatibilicen con el Reglamento C (17). El articulo $4.1 \mathrm{f}$ ) habla de la "solicitud de obtención de cualquier otra prueba", siendo que este concepto de "prueba" en el ámbito del Reglamento debe entenderse en sentido muy amplio, incluyendo por ejemplo la asistencia técnica ${ }^{38}$, y el articulo 10. 4 dice que "El órgano jurisdiccional requirente podrá solicitar al órgano jurisdiccional requerido que utilice los medios tecnológicos de comunicación en la realización de la obtención de pruebas, en particular la videoconferencia y la teleconferencia. Por lo tanto, nada impide que el órgano requerido contacte con el demandado, por ejemplo, por correo electrónico, si el órgano requirente se lo ha facilitado, así se lo ha solicitado y este medio no es contrario en el derecho interno del órgano requerido. Podría así el órgano jurisdiccional de destino emplazar al demandado a fin de que aportara su domicilio correcto o nuevo. Pueden ampliarse conocimientos sobre el funcionamiento de este Reglamento en la referencia a pie de página ${ }^{39}$

\footnotetext{
${ }^{37}$ Reglamento (CE) n ${ }^{0}$ 1206/2001 del Consejo, de 28 de mayo de 2001, relativo a la cooperación entre los órganos jurisdiccionales de los Estados miembros en el ámbito de la obtención de pruebas en materia civil o mercantil (DO L 174 de 27.6.2001, p. 1). En vigor con fecha de 1 de julio de 2001 y de aplicación desde el 1 de enero de 2004.

${ }^{38}$ A.L. Calvo Caravaca Catedrático de $\mathrm{D}^{\mathrm{o}}$ internacional privado Universidad Carlos III de Madrid y J. Carrascosa GonZÁLEZ Catedrático de $\mathrm{D}^{\circ}$ internacional privado Universidad de Murcia "Asistencia judicial internacional. Régimen jurídico en derecho internacional privado europeo y español" pág. 29.

${ }^{39}$ A. Ybarra Bores Profesor Contratado Doctor de Derecho internacional privado Universidad Pablo de Olavide de Sevilla La práctica de prueba en materia civil y mercantil en la unión europea en el marco del Reglamento 1206/2001 y su articulación con el derecho español. Cuadernos de Derecho Transnacional (Octubre 2012), Vol. 4, No 2, pp. 248-265 ISSN 1989-4570 www.uc3m.es/cdt
} 


\section{B) En el ámbito extraeuropeo}

29. Es, principalmente, el Convenio de la Haya de 18 de marzo de $1970^{40}$ sobre obtención de pruebas en el extranjero en materia civil y mercantil que sustituye, en las relaciones entre Estaos contratantes, a los artículos 8 a 16 del Convenio de la haya sobre procedimiento civil de 1954 (artículo 29), el que regula la materia. Con un funcionamiento de comisiones rogatorias muy parecido al establecido en el convenio relativo a la notificación y traslado de documentos, en su artículo 21 a) recoge que "podrán proceder a la obtención de pruebas de toda clase (...)" refiriéndose a las obtenidas por funcionarios diplomáticos o consulares y por comisarios, luego, en mi opinión, el Estado contratante de origen podría solicitar como prueba la averiguación del domicilio del demandado siempre que aporte datos suficientes y el modo de averiguación no fuera contrario al derecho interno del Estado contratante de destino.

\section{C) En el resto del mundo}

30. Algunos de los convenios bilaterales que España ha suscrito son: la declaración de aceptación por España de la adhesión del Reino de Marruecos al Convenio sobre la obtención de pruebas en el extranjero en materia civil o mercantil, hecho en La Haya el 18 de marzo de $1970^{41}$ o el Instrumento de Ratificación del Convenio de Cooperación Jurídica entre el Reino de España y la República Oriental del Uruguay, hecho en Montevideo el 4 de noviembre de $1987^{42}$.

\section{Instrumentos legales en el derecho internacional privado español para la notificación para la obtención de prueba}

31. En cuanto a la normativa de producción interna, el juzgado de primera instancia número Diez de Córdoba siempre pudo haber acudido al principio de reciprocidad establecido en la ley 29/2015 de Cooperación internacional ${ }^{43}$, ley que cubre de forma efectiva la remisión legislativa que hace el artículo 177 de la Ley de Enjuiciamiento Civil, dedicado a la cooperación judicial internacional, a la legislación interna que resulte aplicable en defecto de normas de la Unión Europea o de otros tratados internacionales. Tiene, por lo tanto, un carácter subsidiario, aplicándose exclusivamente a los supuestos no encuadrados bajo normativa legal europea o regulados por convenios bilaterales o multilaterales extranjeros.

32. Esta ley prevé la comunicación judicial directa (artículo 4), siempre, y esto ya es costumbre habitual, respetando las normas de producción interna de cada país, y estableciendo una autoridad central para conseguir la eficiencia de la cooperación. En España esta autoridad central es el Ministerio de Justicia. El artículo 21. 2 indica que: "Siempre que no se oponga a la legislación del Estado de destino, las autoridades españolas podrán practicar las comunicaciones directamente a sus destinatarios por correo postal certificado o medio equivalente con acuse de recibo u otra garantía que permita dejar constancia de su recepción".

33. Interesante reflexión hace Flora Calvo Babío ${ }^{44}$, quien se pregunta si el mencionado artículo podría utilizarse para que, ante el domicilio desconocido de un demandado, un procurador pueda notificarle a través de correo electrónico con acuse de recibido certificado, concluyendo que podría ser posible siempre que la recepción quede correctamente acreditada. A este respecto el Tribunal Constitucional se ha pronunciado en los dos sentidos, diciendo en alguna ocasión que este tipo de notificación no es vá-

\footnotetext{
${ }^{40}$ https://assets.hcch.net/docs/3f8c0c38-ca38-40dd-9df9-7db0fefa69b9.pdf

${ }^{41} \mathrm{https}: / / \mathrm{www} \cdot$ boe.es/diario_boe/txt.php?id=BOE-A-2013-2634

${ }^{42} \mathrm{https}$ ://www.boe.es/diario_boe/txt.php?id=BOE-A-1998-10115

${ }^{43}$ Ley 29/2015, de 30 de julio, de cooperación jurídica internacional en materia civil. BOE núm.182, de 31 de julio de 2015. https://www.boe.es/buscar/doc.php?id=BOE-A-2015-8564

${ }^{44}$ F. Calvo Babí “Las notificaciones en la Unión Europea.” ISSN-e 2255-0488, ISSN 137-2435, N 85, 2004, págs. 70-71
} 
lido si no se respeta el cauce que marca la ley, incluso siendo fehaciente la recepción ${ }^{45}$, y en otras que, aunque no se haya respetado el cauce que marca la ley, sí son válidas si no se produce indefensión. Es decir, para el Tribunal Constitucional la forma es esencial, es ad solemnitatem, por lo que siempre habrá de respetarse, siendo la principal razón la de protección al notificado para que exista fehaciencia de esa notificación. En consecuencia, dice el TC, siempre que exista autentica garantía de que el notificado tiene verdadero conocimiento de la notificación aún por medios extralegales, el respeto al cauce legal de la notificación ya no será preciso, pues carece de sentido.

34. Las vías de transmisión de las solicitudes vuelven a ser muy parecidas a las recogidas en el reglamento 1373/2007, en el convenio de la Haya y en el resto de los convenios de carácter multilateral o bilateral, esto es, vía consular o diplomática, a través de las respectivas autoridades centrales, directamente entre los órganos jurisdiccionales o por conducto notarial. Conocer qué vía es la que mejor conecta con el caso en cuestión, es la tarea del juez español, antes de cursar la solicitud.

35. Respecto a la cuestión que estamos tratando en este trabajo, el juez español debe suspender el procedimiento en tanto en cuanto no se acredite que el documento de notificación o traslado ha sido correctamente notificado, lo que no le impide la adopción de medidas cautelares o provisionales, y podrá, a instancias de parte, proveer lo que considere una vez transcurridos seis meses, aun cuando siga sin tener constancia de la notificación en el extranjero al demandado, medida que tiende a garantizar el derecho a la tutela judicial efectiva del demandante.

36. En cuanto a la obtención de prueba en el extranjero, al igual que con lo visto hasta ahora, el juez español podría utilizar este instrumento para averiguar el domicilio del demandado en el extranjero, siempre que este no fuera desconocido desde el principio, como venimos insistiendo, esto es cuando el intento de notificación haya sido fallido por ser el domicilio facilitado por el demandante erróneo o ya no exista, o el demandado no se encuentre ya en él, como medida de prueba encuadrado en el artículo 31 c) LCJIMC "Si se trata de cualquier otra prueba (...)".

37. Además de la Ley 29/2015 de cooperación jurídica internacional de 30 de Julio en materia civil y mercantil, en el derecho interno español el juez español podrá recurrir a los Artículos 276-278 LOPJ y el Artículo 177 LEC aunque son meros recordatorios de la obligación de observar los cuerpos normativos del derecho europeo, extraeuropeos y los convenios bilaterales y multilaterales internacionales de los que España es miembro o Estado contratante, así como la propia Ley 29/2015 de cooperación jurídica internacional mencionada.

\section{III. ¿Qué pudo hacer el juzgado de instancia y no hizo?}

38. Decíamos al principio, que el caso que comentamos no se encuadra en el supuesto el artículo 156 LEC, esto es domicilio desconocido del demandado, puesto que el demandante si aportó un domicilio en el extranjero a efectos de notificación, y adelantaba que esto era clave en este supuesto para que la activación de todos los instrumentos normativos que hemos ido viendo fura posible, puesto que, si el demandante hubiera manifEstado en su demanda que desconocía el domicilio del demandado, ni el Reglamento 1393/2007 de 13 de noviembre de 2007, ni el Convenio de la Haya de 1 de marzo de 1954 ni el resto de convenios multilaterales o bilaterales que hemos mencionado, podían haberse utilizado, ya que explícitamente queda así regulado ${ }^{46}$. Así también se ha pronunciado el TJUE en casos como C-292/10

${ }^{45}$ STC 40/2020 de 27 febrero 2020. https://www.boe.es/boe/dias/2020/03/26/pdfs/BOE-A-2020-4125.pdf; STC 94/2020 de 20 Julio 2020. https://www.boe.es/diario_boe/txt.php?id=BOE-A-2020-9782

${ }^{46}$ Articulo 1.2 Reglamento (CE) 1393/2007 "El presente Reglamento no se aplicará cuando el domicilio de la persona a la que haya de notificarse o trasladarse el documento sea desconocido"; Artículo $1 \mathrm{CH}$ "El Convenio no se aplicará cuando la dirección del destinatario del documento sea desconocida" 
Cornelius de Visser en su FD $39^{47}$ o en el C-325/11, Alder en su FD24 $4^{48}$ y por ello la importante precisión que hacíamos al principio y que acertadamente hizo la Audiencia Provincial de Córdoba en su auto de 17 Junio 2020 al indicar que no se encontraba el asunto en el supuesto del articulo 156 LEC sino en el del articulo 161.4 LEC, que en cualquier caso, a efectos prácticos, nos remite al 156 LEC pero encuadra el asunto en un escenario normativo distinto.

39. Salvada entonces la aplicación de alguno de los instrumentos normativos que hemos analizado y con los que el juzgado de primera instancia número Diez de Córdoba contaba para el intento de notificación y posterior averiguación del domicilio del demandado, ¿fueron estos agotados antes de dictar el Auto de archivo por "ilocalización del demandado"? La respuesta es no, y por lo tanto el Auto de fecha 17 Junio 2020 de la Audiencia Provincial de Córdoba fue acertado en su estimación parcial del recurso de apelación planteado por el demandante.

40. El artículo $156 \mathrm{LEC}^{49}$ obliga al Letrado de la administración a utilizar todos los medios oportunos para averiguar el domicilio o residencia del demandado, pudiendo dirigirse, en su caso, a los Registros, Organismos, Colegios profesionales, entidades y empresas a que se refiere el apartado 3 del art. 155. 3, y si estas averiguaciones resultaren infructuosas, el Letrado de la Administración de Justicia ordenará que la comunicación se lleve a cabo mediante edictos y que se comunique el nombre del demandado y los demás datos de identidad al Registro Central de Rebeldes Civiles. En ningún caso se considerará imposible la designación de domicilio a efectos de actos de comunicación si dicho domicilio constara en archivos o registros públicos, a los que pudiera tenerse acceso y es reiterada jurisprudencia la obligación de los Juzgados de averiguar el domicilio ${ }^{50}$.

41. Obsérvese que el texto del artículo 156 LEC no restringe los "registros, Organismos, Colegios Profesionales, entidades y empresas", a un ámbito nacional, luego, aunque el artículo 156 LEC sea una norma territorialmente aplicable en el Estado español, nada impide, en mi opinión, que el letrado de la administración no recurra a todos aquellos "registros, Organismos. Colegios Profesionales, entidades y empresas" de cualquier país el extranjero, bien mediante sus propios medios de ser de acceso público, bien mediante la articulación de cualquiera de los Reglamentos o convenios de solicitud de prueba que

${ }^{47}$ STJUE de 15 de Marzo de 2012, C-292/10, Cornelius de Visser, FD 39. ECLI:EU:C:2012:142. "A este respecto, debe recordarse, por una parte, que, en circunstancias en las cuales se desconoce el domicilio del demandado nacional de un Estado miembro, la aplicación de las reglas uniformes de competencia establecidas por el Reglamento 44/2001 en lugar de las vigentes en los diferentes Estados miembros es conforme con el imperativo de seguridad jurídica y con el objetivo de dicho Reglamento consistente en reforzar la protección jurídica de las personas que tienen su domicilio en la Unión, permitiendo al mismo tiempo al demandante determinar fácilmente el órgano jurisdiccional ante el cual puede ejercitar una acción y al demandado prever razonablemente ante qué órgano jurisdiccional puede ser demandado (véase, al respecto, la sentencia de 17 de noviembre de 2011, Hypotečni banka, C-327/10, Rec. p. I-11543, apartado 44)."

${ }^{48}$ STJUE de 19 de diciembre de 2011, C-325/11, Alder, FD 24. ECLI:EU:C:2012:824. "De la interpretación sistemática del Reglamento de que se trata resulta que éste contempla únicamente dos circunstancias en las que la notificación o el traslado de un documento judicial entre los Estados miembros quedan excluidos de su ámbito de aplicación, a saber, por un lado, cuando el domicilio o el lugar de residencia habitual de la persona a la que haya de notificarse o trasladarse el documento sea desconocido, y, por otro lado, cuando esta última ha nombrado un representante autorizado en el Estado en el que tiene lugar el procedimiento."

${ }^{49}$ Artículo 156. "Averiguaciones del tribunal sobre el domicilio. 1. En los casos en que el demandante manifestare que le es imposible designar un domicilio o residencia del demandado, a efectos de su personación, se utilizarán por el Letrado de la Administración de Justicia los medios oportunos para averiguar esas circunstancias, pudiendo dirigirse, en su caso, a los Registros, organismos, Colegios profesionales, entidades y empresas a que se refiere el apartado 3 del artículo 155. Al recibir estas comunicaciones, los Registros y organismos públicos procederán conforme a las disposiciones que regulen su actividad. 2. En ningún caso se considerará imposible la designación de domicilio a efectos de actos de comunicación si dicho domicilio constara en archivos o registros públicos, a los que pudiere tenerse acceso. 3. Si de las averiguaciones a que se refiere el apartado 1 resultare el conocimiento de un domicilio o lugar de residencia, se practicará la comunicación de la segunda forma establecida en el apartado 2 del artículo 152, siendo de aplicación, en su caso, lo previsto en el artículo 158. 4. Si estas averiguaciones resultaren infructuosas, el Letrado de la Administración de Justicia ordenará que la comunicación se lleve a cabo mediante edictos".

${ }^{50}$ STS, Sala Primera de lo Civil, de 14 septiembre 2007 (SP/AUTRJ/444012) 
hemos visto solicitando auxilio a los organismos requeridos para que indagasen según sus procedimientos internos de búsqueda, y finalmente si todo esto fuera infructuoso, podría haber notificado, en España, por edictos, vía artículo 156, que además le obliga, lo que, ya en este avanzado camino de intentos de averiguación del domicilio del demandado, no vulnera el derecho de defensa del demandado y si hubiera salvado e derecho a la tutela judicial efectiva del demandante. Respecto a la notificación mediante edictos sin haber agotado todos los medios de notificación disponibles, el TEDH, en su Sentencia del pasado 15 de diciembre 2020, caso Karesvaára y Njie contra España, se condena al reino de España por vulneración del derecho a un juicio equitativo que recoge el artículo 6.1 del Convenio Europeo de Derechos Humanos. ${ }^{51}$

42. Así se ha pronunciado en numerosas ocasiones tanto el Tribunal Supremo como el Tribunal de Justicia de la Unión Europea. En TJUE en el caso C-327/10 Hypoteční banka a.s. contra Udo, aclarando que "dicho Reglamento no se opone a la aplicación de una disposición procesal interna de un Estado miembro que, con el fin de evitar una situación de denegación de justicia, permite la tramitación de un procedimiento en contra y en ausencia de una persona con domicilio desconocido, siempre y cuando el órgano jurisdiccional que conoce del litigio se haya cerciorado, antes de pronunciarse acerca del mismo, de que se han realizado todas las investigaciones que exigen los principios de diligencia y buena fe para encontrar al demandado"52, y en igual línea argumental el C- 292/10 G contra Cornellus de Viser en su párrafo 56 "dicha restricción (la del derecho de defensa) está justificada a la vista del derecho del demandante a una tutela judicial efectiva, habida cuenta de que sin dicha notificación, ese derecho carecería de eficacia" y $59^{53}$. También el Tribunal Constitucional ha aclarado esta cuestión en su Sentencia $124 / 2006$ de 24 abril 2006. ${ }^{54}$

43. Por lo tanto, el Auto de la Audiencia Provincial de Córdoba estuvo acertado al acoger el motivo de apelación del demandando respecto al incorrecto archivo por parte del juzgado del procedimiento sin agotar todas las vías de averiguación del domicilio y posterior notificación de la demanda, corrigiendo así el error en que este incurrió, y le ordena la averiguación del domicilio.

\section{Conclusiones finales}

44. Tras el análisis jurídico hecho, es obvia la importancia de facilitar al juzgado un domicilio en el escrito inicial de demanda cuando el procedimiento sea transfronterizo, aunque lo creamos incorrecto o esté incompleto, además de otros datos, como teléfono, correo electrónico e incluso cuenta de RRSS, ya que si en el escrito inicial de demanda le decimos al juez que el domicilio es "desconocido", podrán ponerse en marcha por parte del juzgado los recursos del artículo 156 LEC, pero no podrán utilizarse todas las herramientas de los instrumentos legales internacionales que hemos visto. Eso, u obviar en el escrito de demanda que el demandado está en el extranjero y conseguir una sentencia en rebeldía, corriendo el grave riesgo de que pueda no ser valida en el futuro por vulnerar el derecho a la defensa del demandado, pues no podemos perder la referencia de que, antes o después, necesitaremos ejecutarla en el extranjero.

\footnotetext{
${ }^{51}$ https://www.mjusticia.gob.es/es/AreaInternacional/TribunalEuropeo/Documents/CASE\%20OF\%20KARESVAARA\%20AND\%20NJIE\%20v.\%20SPAIN.pdf

${ }^{52}$ STJUE Sala Primera C-327/10, pfo. 55, de 17 noviembre 2011 Hypoteční banka a.s. contra Udo Mike Lindner. ECLI:EU:C:2011:745. http://curia.europa.eu/juris/liste.jsf?language=es\&num=C-327/10;

${ }^{53}$ STJUE Sala primera C-292/10, pfo 59 de 15 Marzo 2012 G contra Cornellus de Viser . ECLI:EU:C:2012:142. http:// curia.europa.eu/juris/liste.jsf?num=C-292/10\&language=ES "por consiguiente, procede responder a la primera cuestión y a la primera parte de la tercera cuestión que el Derecho de la Unión debe interpretarse en el sentido de que no se opone a que se dicte una sentencia en rebeldía frente a un demandado al que, ante la imposibilidad de localizarle, se notificó el escrito de demanda mediante un edicto, de conformidad con el Derecho nacional, siempre que el órgano jurisdiccional que conozca del asunto se haya cerciorado antes de que se realizaron todas las averiguaciones que exigen los principios de diligencia y de buena fe para encontrar a dicho demandado"

${ }^{54}$ STC 14/2006 de 24 Abril 2006 (BOE núm. 125, de 26 demayo de 2006) ECLI:ES:TC:2006:124http:/hj.tribunalconstitucional. es/es-ES/Resolucion/Show/5726
} 
45. Aunque el juzgado deba proceder a ello de oficio, y para ello tiene a su disposición el Punto Neutro judicial con acceso a la Tesorería General de la Seguridad Social, al Instituto Nacional de Estadística, a la Dirección General de Tráfico, a la Agencia Tributaria y otros registros, hay que recordar la importancia del impulso procesal de parte en el ámbito civil, por lo que nunca debemos obviar la labor extrajudicial que podamos hacer, incluso requiriendo los servicios de un detective, si el asunto y, sobre todo su cuantía, lo merecen, y en todo caso solicitando al juzgado que se dirija a cualquier Organismos, Colegios Profesionales, entidades o empresas, cuyos datos le facilitemos nosotros. Desafortunadamente, cuando el litigio traspase las fronteras nacionales y, a pesar de los múltiples instrumentos legales internacionales existentes, la labor de averiguación del domicilio del demandado por la parte interesada, mediante medios privados, tiene un papel esencial. 